\title{
The Business Value of BIM for Asset Owners: A Cross Case Analysis
}

\begin{abstract}
Purpose - The purpose of this paper is to investigate and identify the activity systems that drive Building Information Modelling (BIM) business value in Asset Management (AM). The utilisation of BIM has widened in scope, functionality, flexibility and interoperability to support the AM business process. However, research concerning BIM business value in AM has been inadequate despite its considerable potential and significance in the attainment of organisational objectives. The realisation of BIM business value requires a concerted effort by the asset owner to be able to determine and appraise the critical activities that drive business value in AM.
\end{abstract}

Design/methodology/approach - The study adopted a qualitative research approach based on a multi-case study strategy that aimed to identify the key business processes that drive BIM business value in AM. The study involved a three-stage research design using interviews and document analysis to facilitate a cross-case analysis from the perspective of the activity systems and dimensions of BIM governance.

Findings - The paper identified six critical activity systems that drive BIM business value for an asset owner: BIM strategy, contract management, lifecycle management, maintenance management, work-order management and value realisation management. The study found that the most developed activity system is the BIM strategy, and the least is value realisation management across all cases. Also, the paper points out that the most proficient BIM governance dimension is Process, and the least is People across the three cases. The study noted that the ability of an asset owner to realise BIM business value has maturity undertones and that the asset owner could derive BIM business value, if the six activity systems are effectively executed and continuously improved to an advanced stage of maturity.

Originality - An original contribution of the study is the development of the understanding of asset owners in relation to the discovery of key activity systems that drive BIM business value in AM. Another significant contribution of this paper is the demonstration of a novel approach to evaluate organisational maturity of asset owners from the perspectives of the activity systems and BIM governance dimensions of people, process and technology.

Paper type - Case Study

Keywords - Building Information Modelling, Asset management, Value Realisation, Management, Maturity. 


\subsection{INTRODUCTION}

Asset Management (AM) involves a number of activities, such as collecting asset information, planning maintenance, scheduling activities, managing inventory, data analysis and performance improvement. Recently, Building Information Modelling (BIM) is transforming how buildings are designed, constructed and operated in the Architecture, Engineering and Construction (AEC) industry (McArthur, 2015). Collecting and analysing asset data using traditional methods for AM processes consumes a lot of time and effort. Therefore, to effectively execute AM tasks, asset owners utilise: Computerised Maintenance Management Systems (CMMS); Integrated Workspace Management Systems (IWMS); Computerised Asset Management Software (CAMS); Energy Management Systems (EMS); Computer Aided Facilities Management (CAFM); Internet of Things (IoT); and Building Information Modelling (BIM) (Codinhoto and Kiviniemi, 2014; Guillen et al., 2016). These Digital Information Technologies (DITs) help to facilitate the effective delivery of consolidated operational building performance data (Love et al., 2013; McArthur, 2015). The DITs are designed to gather all related asset maintenance data to improve information delivery, risk mitigation and performance monitoring. However, this area has received little attention from researchers (Love et al., 2013; Love et al., 2014; Munir et al., 2018).

For the asset owner, the adoption of the right BIM systems, AM systems, Facility Management (FM) systems, techniques and strategies are vital for the achievement of business objectives. Poor AM practices can lead to severe consequences as organisational goals are mostly tied to the effective performance of key assets. Access to the right information, at the right time, in the right format, against the right query, to the right department and by the right personnel is crucial in the effective management of assets. Also, the utilisation of BIM has widened in scope, functionality, flexibility and interoperability to support the business processes of the asset owner (Love et al., 2013). Similarly, BIM has been claimed to deliver asset information for AM tasks in an efficient manner (Brous et al., 2015). Love et al. (2014) suggested that BIM utilisation can enable strategic business outcomes for the asset owner. Brous et al. (2015) reported that asset owners leverage data from their assets using BIM within their organisation and through the supply chain. However, the benefits of BIM in AM are yet to be fully realised.

There are many challenges that hinder the realisation of value from BIM investments. Henderson et al. (2014) claimed that the AEC industry is replete with half-finished BIM systems that complicate processes without adding the value expected. Moreover, asset owners often believe that BIM systems will automatically drive benefits and provide maintenance solutions without understanding that they are mere tools that facilitate effectiveness. Love et al. (2014) argued that the process of BIM implementation has to be proactively managed and that technology alone cannot deliver business outcomes. Therefore, to identify BIM business value, a concerted effort to research is required to identify the key business activities that drive business value in AM. There is a need for a process-oriented approach to evaluation that goes beyond the traditional boundaries of 
financial evaluation (Bakis et al., 2006; Love et al., 2013). Furthermore, organisations need to understand the socio-economic effects that BIM enables (Vass and Karrbom Gustavsson, 2014). As such, this study focused on the key activities that drive BIM business value for an asset owner and how they can be appraised. Business value in the context of this study is defined as the positive effects in the form of benefits derived by an asset owner as a result of executing business processes. Similarly, BIM business value is defined as the benefits generated by an asset owner through the utilisation of BIMbased processes in the effective management of built assets. In addition, activity systems in this study refer to the critical BIM-based business processes that drive value for the asset owner during asset operation. BIM governance dimensions are defined as the factors that determine the control and regulation of the BIM implementation process. Also, in the context of this study, an asset is referred to as a physical asset, specifically built, and includes other types of assets that make it functional. Generally, the research focused on built assets that are owned and operated by an organisation.

\subsection{BIM BUSINESS VALUE IN ASSET OPERATIONS}

BIM is defined as a set of interacting people, processes and technologies that produce a methodology to manage the data of a building digitally, its performance, planning, construction, and later its operation (Succar et al., 2007; Eastman et al., 2011). This study views BIM from the perspective of Building Information Management, where ' $\mathrm{M}$ ' refers to Management instead of Modelling (Parsanezhad and Dimyadi, 2014). However, the lack of understanding and empirical evidence concerning the benefits of BIM-based processes in AM is a crucial barrier to the implementation of BIM in AM. Thus, asset owners are faced with the challenge of making the decision to implement BIM based on uncertain benefits (Dakhil et al., 2016). The asset owner may benefit when BIM is integrated with projects, programmes and portfolios throughout the entire lifecycle of the building. The availability of reliable data from BIM may enable the asset manager to make intelligent and sound decisions that will help to develop comprehensive maintenance strategies that could optimise the facility. Currently, asset owners have realised marginal benefits from BIM in the operations and use phase, and this is due to the lack of organisational synergy between people, processes and technological systems (Bosch et al., 2015). Another challenge of effective asset maintenance is that there is no central source of information, especially for organisations with non-sophisticated BIM or AM systems. Therefore, time is wasted in filtering data and searching for accurate asset information that is only relevant to a specific maintenance task. However, this data can be easily accessed by the asset manager when it is digitally generated, linked, managed and stored.

Asset managers require information that is accurate, timely and reliable in order to manage their assets effectively. However, asset owners lose significant amounts of resources by adopting inappropriate asset maintenance practices. Generally, asset maintenance is viewed by organisations as an activity that costs money because it does 
not visibly include value-adding activities. However, this opinion is changing because organisations increasingly understand that effective asset maintenance is a central point for profitability. The change from a reactive to a proactive maintenance culture and its attendant impact on organisational processes will yield value in both profitability and sustainability for the asset owner (Henderson et al., 2014). A particular repair may cost three times more when using a reactive strategy compared with a preventive maintenance strategy (Mobley, 2004). Therefore, for an asset owner, selecting the most efficient asset maintenance strategy could make significant gains in the current competitive business climate. It is widely considered that a $1 \%$ improvement in plant uptime will add $4-8 \%$ to the bottom-line, and $1 \%$ reduction has a similar reverse effect for an asset owner (Henderson et al., 2014). This comparison showed that the effective execution of key AM activities and sound maintenance strategies have significant effects on the financial performance of an asset owner. Hence, there is a need to explore the critical BIM-based processes that drive value in AM.

Some studies have researched BIM business value (Kiviniemi and Codinhoto, 2014; Love et al., 2014; Sanchez et al., 2016), but none offered the investigation key business processes in AM from the perspective of BIM, AM and value realisation management. BIM systems have the potential to provide the data needed to establish a robust maintenance strategy to manage key assets effectively. However, one of the barriers to BIM adoption in the operations and use phase is the requirement for operations personnel to possess strategic and tactical skills in order to plan and manage organisational resources in relation to task requirements (Pärn et al., 2017). Without further exploration, asset owners may not be able to understand BIM-based business processes in AM and how they derive value. Moreover, requirements for the successful implementation of BIM in the operations and use phase are still unclear (Becerik-Gerber et al., 2012). Similarly, Dakhil et al. (2016) highlighted the importance and the need to develop an understanding of BIM benefits-maturity relationship in the AEC industry. Hence, the rationale for this study, which is to enhance the understanding of asset owners concerning the relationship between critical BIM-based processes, business value and maturity in AM.

\subsection{METHODOLOGY AND RESEARCH QUESTIONS}

This section outlines the methodology and research question for the study.

\subsection{RESEARCH QUESTION}

This research utilised a multi-case study strategy to investigate and identify the activity systems that drive BIM business value in AM. It also sought to evaluate the maturity of activity systems in relation to the organisational tendency of realising BIM business value. The study addressed the following research questions:

- What are the critical AM business processes that drive BIM business value in AM?

- How do they relate to business process maturity? 


\subsection{RESEARCH METHODS}

To achieve the research objectives, the study adopted exploratory and descriptive approaches (Saunders et al., 2012). Exploratory research methods were utilised to identify the vital business processes that drive BIM business value in AM, while descriptive research methods were used to convey the characteristics of BIM-based business processes in AM in relation to the organisational tendency to realise BIM business value. Furthermore, the study adopted a deductive approach using a multi-case study strategy (Yin, 2003). The case study methodology is an empirical inquiry that helped to investigate the phenomena of BIM business value in real-life contexts (Saunders et al., 2012). It also enabled the research data analysis within each and across different perspectives (Yin, 2003). Based on this premise, the study adopted the BIMAsset Maturity Model (BAMM) in appraising business process maturity from single and multiple viewpoints in order to comprehensively evaluate the phenomenon of BIM business value (Munir et al., 2019). The BAMM was utilised because the study was unable to find any maturity model or assessment sheet that was applicable to BIM-based business processes in AM and the context of value realisation.

\subsubsection{CASE STUDY SELECTION}

This study investigated three large asset owners utilising BIM in asset operations.

- Senate Properties (referred to as Company A) is a Finnish state-owned company that manages all public owned built assets and owns about 9,300 buildings with a total of $6,100,000 \mathrm{~m}^{2}$. The study investigated a department in Company A that utilises BIM in building asset operations. At the operational level, the department is responsible for maintaining public-owned buildings and providing a functional, safe and supportive work environment. Company A had mandated the use of BIM in all its projects above $€ 2 \mathrm{~m}$ since 2007 , and by 2018 the limit was reduced to $€ 1 \mathrm{~m}$. At the strategic level, the department is responsible for developing the organisational BIM requirements, which later formed a key component of the Common BIM (COBIM) 2012 Standards of Finland.

- University of California San Francisco-Health (UCSF) (referred to as Company B) is a health sector owner-operator in the US that owns and manages about 125 buildings with over $280,000 \mathrm{~m}^{2}$. The study examined a department in Company B that maintained physical and built assets. At the strategic level, the department is involved in identifying innovation in asset operations and in designing strategies for their implementation. At the operational level, the department is responsible for all daily (24-hour) operations for the infrastructure, physical buildings and plants.

- Technical University Denmark (DTU) (referred to as Company C) is a Danish education sector client that owns about 378 buildings and maintains $660,000 \mathrm{~m}^{2}$. The department investigated in Company $\mathrm{C}$ is responsible for planning, designing, constructing and operating facilities. At the strategic level, the department is 
responsible for developing and implementing strategies for planning, coordination and communication within the organisation during project delivery. At the operational level, the department is responsible for operating the built assets.

During data collection, the population of asset owners who were implementing BIM in asset operations was not known; and this led to the consideration that random sampling was impracticable. Also, random sampling was neither necessary nor preferable since only a limited number of cases can be studied due to the adopted research strategy (Eisenhardt, 1989). Furthermore, it was essential to select samples based on the awareness of case characteristics (Denscombe, 2010). As a result, a type of purposive sampling, called operational construct sampling, was adopted (Patton, 2002). All three cases were purposefully selected and were asset owners that utilised BIM in asset operations. The criteria used for selecting participants were:

- Participants had an advanced level of knowledge and understanding of BIM in AM.

- Participants were senior staff in charge of BIM-based processes in AM.

- Participants were key stakeholders and high-level decision-makers of BIM-based AM operations in their organisations.

- Participants interacted with high, middle and lower-level personnel in the execution of BIM-based processes during asset operations.

To ensure validity, participant validation was conducted (Saunders et al., 2012). This was achieved by sending the interview transcripts and analysed data for authentication in terms of accuracy of respondent accounts.

\subsubsection{DATA COLLECTION AND ANALYSIS}

The research design was based on the cross-case assessment of the business processes of three asset owners. It was carried out in two phases, namely the literature review and multi-case study analysis. The literature review helped to explore aspects concerning BIM business value in AM. The second phase, which is the multi-case study, was carried out in four stages: interviews, document analysis, within-case appraisal and cross-case analysis. Firstly, in-depth semi-structured interviews were employed to gather data on aspects that impact BIM business value in the business processes of the asset owners. Secondly, organisational documents were sourced for data analysis. Thirdly, a withincase analysis was conducted for all the cases in order to appraise and score them independently. These individual cases were analysed based on BIM governance dimensions and activity systems that drive business value for the asset owner (Munir et al., 2019). Lastly, these cases were then compared in the cross-case analysis. The cases were finally presented in a BIM business value realisation maturity assessment model in Section 3.7. Figure 1 shows the methodological process of the study. 


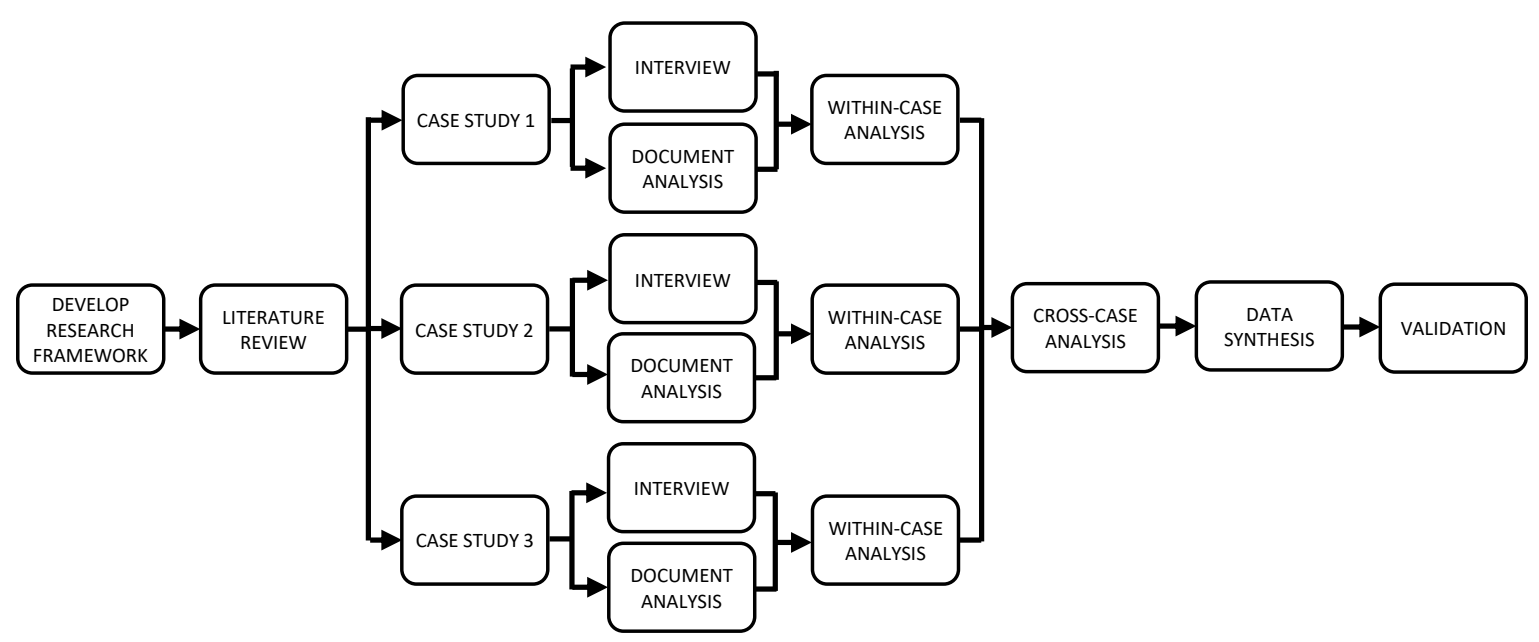

Figure 1: Research Methodology

This multi-case study adopted qualitative techniques for data collection and analysis. This included interviews and document analysis, which were used to collect data on organisational processes, experiences, activities and practices (Saunders et al., 2012). Three in-depth semi-structured interviews were conducted, namely one for each case study. The primary purpose of the interviews was to elicit qualitative accounts of organisational BIM strategies, AM business processes and BIM value realisation activities. Furthermore, the NVivo ${ }^{\mathrm{TM}}$ software was used to transcribe and analyse the primary data (Saunders et al., 2012). Coding was utilised for easy analysis, and the indexing and retrieval of primary data (Boyatzis, 1998). These codes were classified into categories and further linked to the study themes. The primary data categories comprise one or more codes, which were used in the data analysis and discussion.

Furthermore, thematic analysis, as a qualitative research technique, was used to facilitate the identification, analysis and reporting of themes within the study data (Boyatzis, 1998). During the literature review, themes were established, which guided certain aspects of the data analysis. Documents related to organisational protocols, strategies, standards and value realisation management activities were sourced from participants in order to investigate the phenomenon further. Document analysis was conducted, and the findings were reported alongside the interview findings (Figure 2). Specifically, the qualitative, cross-case analysis helped to identify patterns and themes that showed the nature and links between certain AM activities and BIM business value for asset owners. A cross-case analysis is suitable for synthesising evidence from multiple cases within a multi-case setting (Miles and Huberman, 1994). Primarily, the cross-case analysis technique utilises a toolbox of cross-case displays and matrices that organise data according to variables or cases for the easy comparison of differences and commonalities in activities, processes and units of analysis (Cruzes et al., 2015). While such assessment may appear to be subjective, this was appropriate considering the nature of this study. 


\subsection{RESULTS: CROSS CASE ANALYSIS}

This section presents the results of the findings from the interviews and document analysis. Data from the case study interviews showed that the following BIM-based activities have the potential to drive BIM business value: BIM strategy, contract management, lifecycle management, maintenance management, work-order management and value realisation management. These six key business processes are referred to as activity systems in this study, and they are defined as:

- BIM Strategy: This is a critical BIM-based business process that drives business value for the asset owner. BIM strategy involves the overall organisational policy when employing BIM in the planning and directing of asset operations and management. It covers broad organisational BIM approaches, which include: change, performance, and stakeholder management; short and long term organisational policy for BIM adoption; and the definition of organisational information needs for BIM-based processes.

- Contract Management: This involves the organisational oversight and implementation of BIM-based processes in the creation, negotiation, analysis, performance monitoring, risk management and full execution of contractual obligations, while minimising risk and maximising financial and operational performance. Contract management has been identified as an important BIMbased business process that drives business value for the asset owner. This covers: tendering procedures, performance monitoring, invoice tracking, and compliance checking.

- Lifecycle Management: As a key BIM-based business process that drives business value for the asset owner, lifecycle management involves the organisational use of BIM in all successive stages of asset development, namely from inception to disposal. It involves a holistic approach to organisational BIM standards and implementation across asset development stages, data integration, process standardisation, technological capability, and human inclusion.

- Maintenance Management: This is centred around the effective management of resources and systems within an organisation with the aim of checking compliance, controlling costs and optimising efficiency through BIM-based processes. Maintenance management has been identified as a significant BIMbased business process that drives business value for the asset owner. This involves the technical, administrative and managerial actions adopted in utilising a BIM-based approach to carry out preventive, predictive, proactive, passive and reactive maintenance practices.

- Work-Order Management: This is a crucial business process that involves a comprehensive organisational approach to utilise BIM-based processes in creating, scheduling, updating, budgeting, analysing, prioritising and tracking 
work-orders that derive value for the asset owner. Work-order management within an organisation comprise: process standardisation and workflows; identification of user characteristics; definition of individual and organisational information needs; automated cost estimates and invoicing; and supply chain integration.

- Value Realisation Management: As a fundamental BIM-based business process, value realisation management involves the establishment of organisational protocols for the definition, planning, identification, monitoring and realisation of BIM business benefits within the organisation across and different stages of the asset lifecycle. Value realisation management within an organisation include: the development of business value evaluation techniques; definition and monitoring of KPIs; and exploitation of change and stakeholder management strategies.

The six activity systems were appraised from the perspective of governance dimensions of people, process and technology as proposed by Munir et al. (2019). The governance dimensions are defined as:

- People: This refers to the human aspect that is central to any organisational activity, and in this context, the implementation of BIM during asset operations. The evaluation covers organisational BIM implementation strategy, collaboration, training, and capability of every activity system.

- Process: This represents the protocols that control the entire business activities of an organisation, and in this context, the implementation of BIM during asset operations. The evaluation covers organisational BIM standards, defined roles, use of BIM data, asset lifecycle integration, supply chain inclusion, and value realisation management activities for every activity system.

- Technology: This refers to the physical and technical infrastructure that provides a medium to achieve organisational objectives through BIM. The evaluation covers organisational systems (DITs), systems architecture, interoperability, data integrity, and data accessibility of every activity system.

The case studies were appraised individually and comparatively based on the BAMM tool suggested by Munir et al. (2019). The adopted BAMM tool employed five levels of BIM maturity as well as the following scoring:

- Ad-hoc - 1 Point

- Defined - 2 Points

- Managed - 3 Points

- Integrated - 4 Points

- Optimised - 5 Points

For the cross-case analysis, the scoring of each level of maturity is allocated a scale of 1 5 points. Each case study is appraised based on the maturity of each governance dimension (people, process and technology) against the activity systems (BIM strategy, contract management, lifecycle management, maintenance management, work-order 
management and value realisation management). These two elements formed the main focus of analysis. Furthermore, the overall scores for each governance dimension in relation to the activity systems are aggregated into a total numerical score. A summary of the cross-case analysis is shown in Figure 2 , and the maturity summary of each case is represented in Section 3.7.

\begin{tabular}{|c|c|c|c|c|c|c|c|c|c|c|c|c|c|c|c|c|}
\hline \multirow[b]{2}{*}{ S/NO } & \multirow[b]{2}{*}{ DESCRIPTION } & \multicolumn{5}{|c|}{ COMPANY A } & \multicolumn{5}{|c|}{ COMPANY B } & \multicolumn{5}{|c|}{ COMPANY C } \\
\hline & & 1 & 2 & 3 & 4 & 5 & 1 & 2 & 3 & 4 & 5 & 1 & 2 & 3 & 4 & 5 \\
\hline \multirow[t]{4}{*}{1} & BIM STRATEGY & & & & & & & & & & & & & & & \\
\hline & A. PEOPLE & & & & $\mathrm{X}$ & & & & & $\mathrm{X}$ & & & & $x$ & & \\
\hline & B. PROCESS & & & & $x$ & & & & & $x$ & & & & & $x$ & \\
\hline & C. TECHNOLOGY & & & & $\mathrm{x}$ & & & & & $x$ & & & & & $\mathrm{X}$ & \\
\hline \multirow[t]{4}{*}{2} & CONTRACT MANAGEMENT & & & & & & & & & & & & & & & \\
\hline & A. PEOPLE & & & & $x$ & & $x$ & & & & & & $x$ & & & \\
\hline & B. PROCESS & & & & $\mathrm{X}$ & & $\mathrm{X}$ & & & & & & & $x$ & & \\
\hline & C. TECHNOLOGY & & & & $x$ & & $x$ & & & & & & $x$ & & & \\
\hline \multirow[t]{4}{*}{3} & LIFECYCLE MANAGEMENT & & & & & & & & & & & & & & & \\
\hline & A. PEOPLE & & & & $\mathrm{X}$ & & & & & $x$ & & $\mathrm{X}$ & & & & \\
\hline & B. PROCESS & & & & $\mathrm{x}$ & & & & & $\mathrm{x}$ & & & $\mathrm{x}$ & & & \\
\hline & C. TECHNOLOGY & & & & $\mathrm{x}$ & & & & & $x$ & & $\mathrm{x}$ & & & & \\
\hline \multirow[t]{4}{*}{4} & MAINTENANCE MANAGEMENT & & & & & & & & & & & & & & & \\
\hline & A. PEOPLE & & & & $\mathrm{x}$ & & & & & $x$ & & & & $x$ & & \\
\hline & B. PROCESS & & & & $\mathrm{X}$ & & & & & $\mathrm{X}$ & & & & & $\mathrm{X}$ & \\
\hline & C. TECHNOLOGY & & & & $\mathrm{X}$ & & & & & $x$ & & & & $x$ & & \\
\hline \multirow[t]{4}{*}{5} & WORK-ORDER MANAGEMENT & & & & & & & & & & & & & & & \\
\hline & A. PEOPLE & & & & $\mathrm{X}$ & & & & $\mathrm{X}$ & & & & & $x$ & & \\
\hline & B. PROCESS & & & & $\mathrm{x}$ & & & & & $x$ & & & & $x$ & & \\
\hline & C. TECHNOLOGY & & & & $\mathrm{x}$ & & & & & $\mathrm{x}$ & & & & $x$ & & \\
\hline \multirow[t]{5}{*}{6} & VALUE REALISATION MANAGEMENT & & & & & & & & & & & & & & & \\
\hline & A. PEOPLE & & & $\mathrm{x}$ & & & & $\mathrm{x}$ & & & & $\mathrm{x}$ & & & & \\
\hline & B. PROCESS & & $\mathrm{x}$ & & & & & $\mathrm{x}$ & & & & $\mathrm{x}$ & & & & \\
\hline & C. TECHNOLOGY & & $x$ & & & & & $\mathrm{x}$ & & & & $\mathrm{x}$ & & & & \\
\hline & TOTAL SCORE & \multicolumn{5}{|c|}{67} & \multicolumn{5}{|c|}{56} & \multicolumn{5}{|c|}{44} \\
\hline
\end{tabular}

Figure 2: Cross-case assessment sheet

The three case studies were assessed (Figure 2) with Companies A, B and C having overall scores of 67, 56 and 44, respectively. This data is further presented in a radar diagram (Figure 3): 


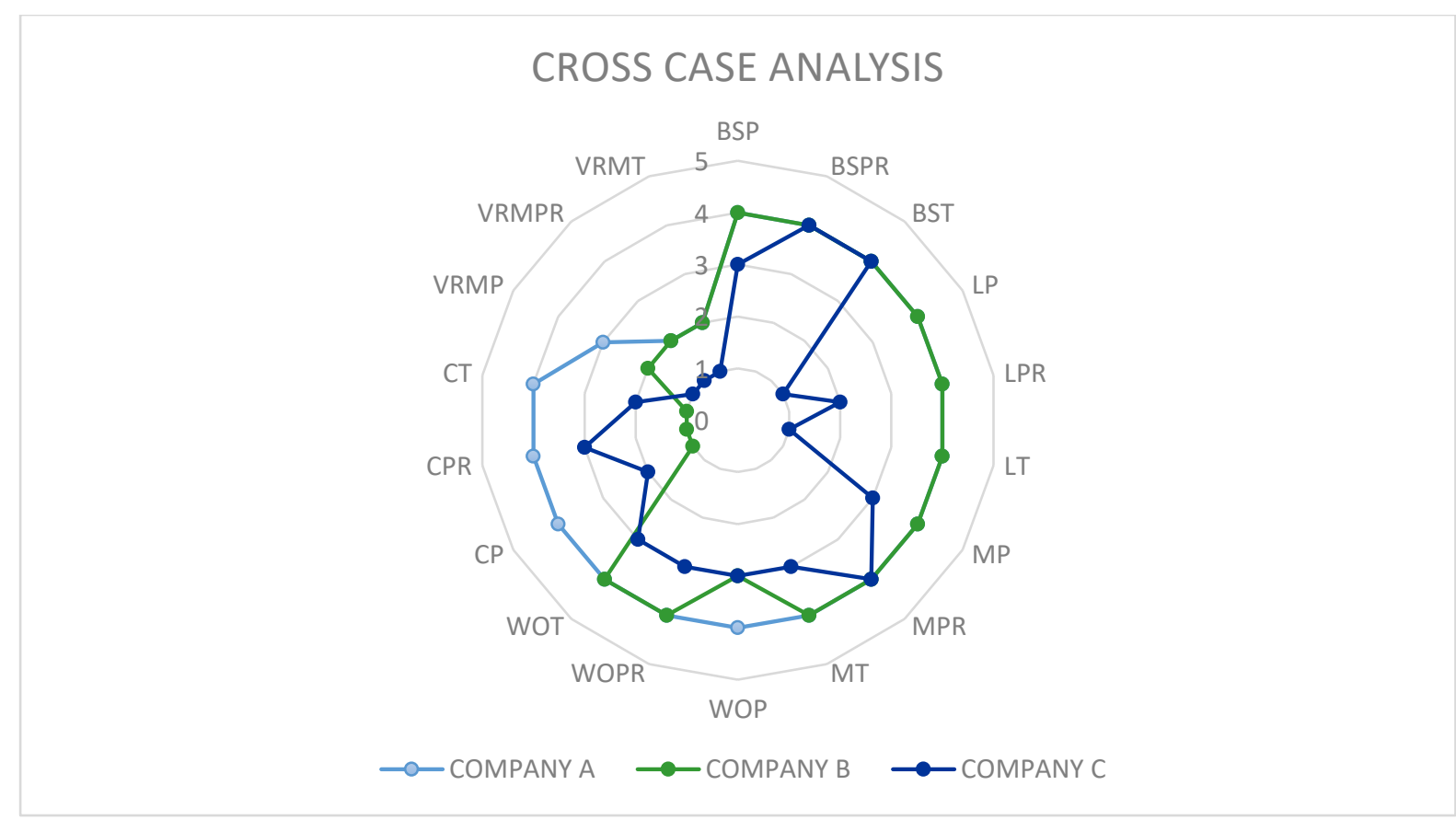

Figure 3: Radar diagram showing a comparison of the three case studies based on activity systems maturity

BSP-BIM Strategy-People; BSPR-BIM Strategy-Process; BST-BIM Strategy-Technology; LP-Lifecycle Management-People; LPRLifecycle Management-Process; LT-Lifecycle Management-Technology; MP-Maintenance Management-People; MPR-Maintenance Management-Process; MT-Maintenance Management-Technology; WOP-Work-Order Management-People; WOPR-Work-Order Management-Process; WOT-Work-Order Management-Technology; CP-Contract Management-People; CPR- Contract ManagementProcess; CT-Contract Management-Technology; VRMP-Value Realisation Management-People; VRMPR-Value Realisation Management-Process; VRMT-Value Realisation Management-Technology

The radar diagram shows a comparison of the three cases with respect to the six activity systems. The cross-case analysis will be discussed in more detail in the following sections.

\subsection{BIM STRATEGY}

Company A has many objectives for implementing BIM in their AM and FM processes, which centre around the execution of an asset digitalisation programme that aims to: (a) Develop solutions that provide real-time, automated information for decision making, space management, asset maintenance and service delivery; (b) Enhance the efficiency of operations and improve quality delivery; (c) Develop the understanding and correlation of phenomena related to energy consumption, indoor conditions and user satisfaction; (d) Improve the indoor conditions and increase end-user productivity; and (e) Provide new services for users and enable conducive indoor conditions in the workplace (Figure 4). Company A focused on new business processes with the aim of enhancing space and asset management by introducing new digital tools and operating models. 


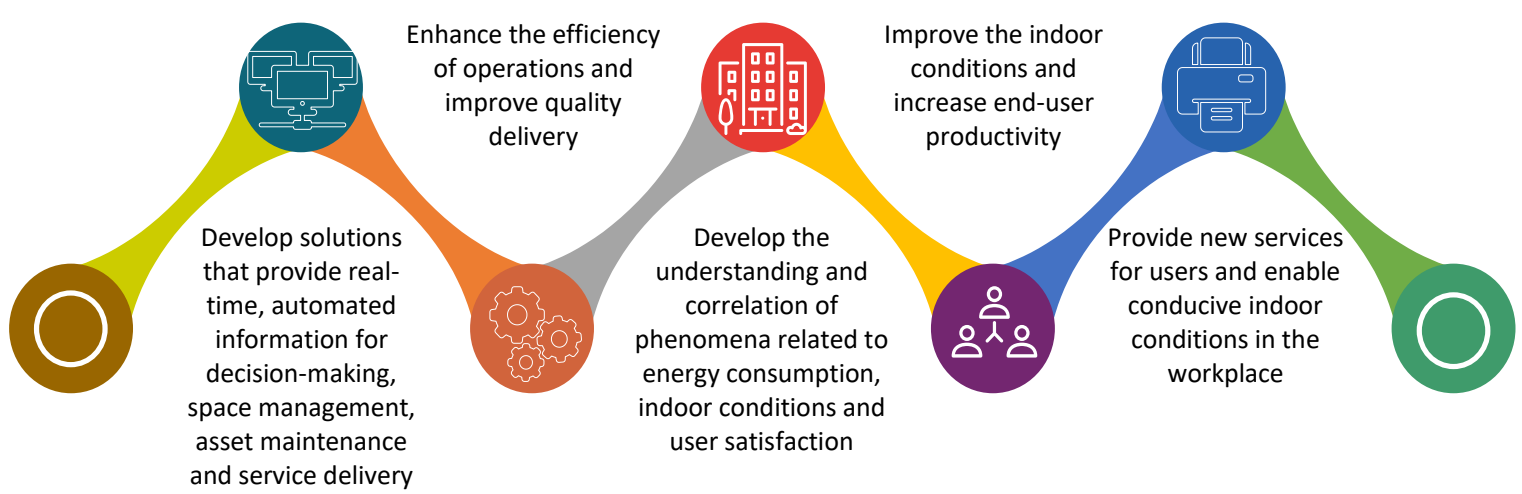

Figure 4: Company A BIM Strategy

On the other hand, Company B adopts a dynamic strategy to the implementation and utilisation of BIM in their organisation, which include (Figure 5); (a) Usability and safety; (b) Data maintainability; (c) Data accuracy; (d) Speed and reliability; and (e) Flexibility and predictability. To achieve these business objectives, Company B has: (1) Utilised a lifecycle approach from design to operations; (2) Defined the requirements from the construct of BIM; (3) Built new systems and business processes; (4) Developed bilateral exchange relationships between the CMMS and digital twin (real-time building information model); and (5) Partnered in software development. To ensure a lifecycle approach, Company B utilised Integrated Project Delivery (IPD) to break down their vertically stacked departments, which were not communicating effectively during the project delivery process. Secondly, Company B discovered early in the BIM process, the need for an information requirement template, which specifies all the statutory submittal data, operations data, preventative and predictive maintenance data. Thirdly, Company $\mathrm{B}$ has automated all its maintenance activities through the CMMS system to reduce the vagaries in the amount of process touchpoints required in registering maintenance activities. Fourthly, Company B is disposed to a bilateral communications approach between the CMMS and their interpretation of the digital twin, which is a living as operated model utilised for asset operations. This strategic approach helps to design a bilateral exchange or relationship between the CMMS as an interpretive tool of the building information model, where the two can read each other and update each other as changes are made to one or the other. Finally, Company B has identified strategic opportunities of partnering with multinational corporations that collect data from their critical equipment or assets. This data is sourced out of a global sample to determine the optimum conditions of operating the equipment or assets. 


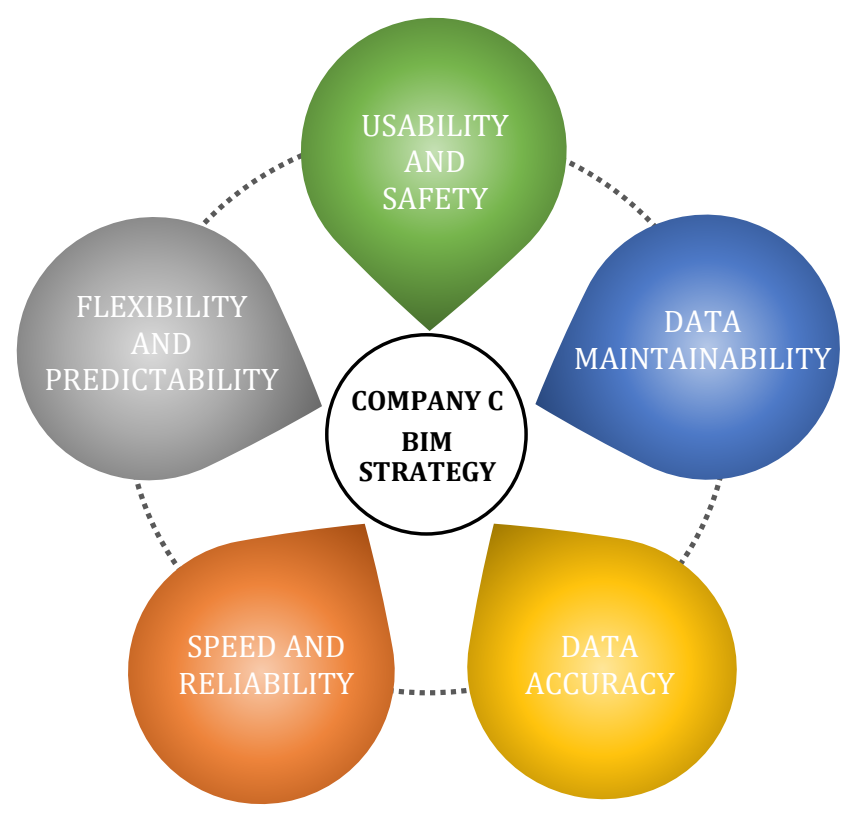

Figure 5: Company C BIM strategy

In comparison, Company $\mathrm{C}$ has many objectives for implementing BIM in the operations and use phase, which centre around integrated systems, data quality and system flexibility for business processes in the operational department. Company C's BIM strategy involves linked data. They recognise that BIM cannot contain all data and perceive it as a medium for linking data. Furthermore, Company $\mathrm{C}$ has partnered a software provider to develop flexible systems to accommodate their business processes. The decision to have a technology partner arose as a result of the technological limitations of existing software in the market place. Furthermore, Company C acknowledges the iterative learning process of utilising data in managing assets as they have developed an in-house information requirement template for day-to-day operations. These requirements are stated in their contracts, and they define how AM data should be delivered from the design and construction processes.

This activity system has the highest average across all three cases. The analysis ( $\underline{\text { Figure }}$ 3) shows that Companies A and B have the most comprehensive organisational BIM strategy, whilst Company $\mathrm{C}$ has the least comprehensive BIM strategy. However, Company $\mathrm{C}$ has a relatively matured BIM strategy rating, as its people dimension is only a point lower than Companies B and C, due to its bottom-up approach.

\subsection{CONTRACT MANAGEMENT}

Company A has fixed processes for contracts that are fully automated from tender to handover and includes payment tracking. As a strategy, Company A uses cost-plusincentive contracts, which allows for a negotiated fee to be adjusted later based on the success of the service request. This approach aims to enhance the performance of the service providers. Based on set Key Performance Indicators (KPIs), BIM-based processes are used throughout the whole process to measure the performance of maintenance 
service providers. If the performance is good, Company A will pay more, and if satisfaction is low or if service requests are not completed on time, part of the service provider's fee would be taken off. In Company B, contract management is the least developed activity system. This is due to the organisational structure, where in-house personnel usually carry out asset maintenance. Company B has highlighted that they are yet to roll out services for monitoring contracts through BIM and CMMS. In comparison, the systems in Company $\mathrm{C}$ perform a function for contract management. Also, Company $\mathrm{C}$ has an in-house ticket system for contracts management, which was developed and is utilised by Company $\mathrm{C}$ and its suppliers. These systems contain the organisational contract database that keeps a record of the operations and helps track payments.

Comparatively, this is the second-least developed activity system across all three cases. The analysis (igure 3 ) shows that, overall, Company A has the most methodical approach towards contract management. Company $\mathrm{C}$ has the second-highest rating, whilst Company B has the lowest because there are currently no established organisational procedures for contract management.

\subsection{LIFECYCLE MANAGEMENT}

Company A derives business value from BIM in the lifecycle management of assets through the utilisation of BIM-based asset data in the lifecycle planning of built assets. Here, Company A derives value through the planning and execution of annual maintenance plans that are based on historical records, such as maintenance, energy consumption and service requests. Also, Company A utilises BIM in planning the work environment to support wellbeing and productivity by improving working conditions. Whereas in Company B, BIM utilisation in the operations and use phase enables them to break the silos of disciplines within the organisation to conduct full circle planning. This approach allows stakeholders in the operations phase to participate and contribute not only to the design development but also to validate as-built data, populate the work-order system, and develop a preventative maintenance strategy. Also, the asset knowledge database from the BIM systems enable facility condition assessments and planning from which long-term strategic plans are drawn. Another aspect that is of value to Company $B$ was in a case where the operational department ensured that flags as $600 \times 600 \mathrm{~mm}$ grids were built in the designs to ensure that no structures were assigned in those areas. All the designers had to work their plans around them and were instructed to locate serviceable parts and devices adjacent to the working spaces. This approach provided a practical solution to an operational problem because, in Company B, it took a lot of time and effort in locating and determining where and how to access an area to perform a maintenance repair. On the other hand, Company $\mathrm{C}$ utilises BIM for the long-term planning of its facilities. The system has a financial tool that is used to allocate funds and plan organisational resources for annual preventive maintenance activities. The data generated is used to forecast and schedule maintenance activities in order to apply for funding to senior management within Company $\mathrm{C}$. 
Comparatively, this activity system has the third-lowest average across all three cases. The analysis (Figure 3 ) shows that Companies A and B have the most sustainable approach in lifecycle management, whilst Company $\mathrm{C}$ has the least defined approach.

\subsection{MAINTENANCE MANAGEMENT}

Company A has utilised BIM-based processes for over 18 years in project delivery. They manage all of their maintenance activities through BIM and other DITs. Company A stated it is 'impossible' to work without existing systems due to the level of dependency in managing the large datasets that each building produces, and considering their huge portfolio, which totals about 9,300 built assets. Company A has many databases for maintenance management, for example: the project maintenance database, building fabric information database, energy management database, and CMMS. Company A has derived the business value of BIM in maintenance management through reduced routine work times and an improved predictability of asset failure. In contrast, Company B utilises BIM for maintenance management to analyse and query data by evaluating the KPIs of various user groups or stakeholders within the organisation. This capability has enabled the asset maintenance strategy of Company B to become mature and more predictive than reactive. In terms of the value proposition of BIM in asset operations, Company B stated it is 'absolutely certain' that BIM will reduce the number of their failed asset interventions when it is fully rolled out on the whole asset portfolio. These KPIs are used to report from the operational level to strategic management within the organisation. Another benefit that Company B derives is the better management of maintenance activities by the allocation of workload for operational personnel. On the other hand, Company $\mathrm{C}$ utilises BIM-based processes for maintenance management in the operation of its assets. The BIM and CMMS platform has a number of functionalities, including a room database, building database, document database and contract database. These are utilised for activity management in the planning of preventive maintenance. This helps Company $\mathrm{C}$ to integrate information and rooms or spaces, and to enable operational personnel to identify the kind of information needed for a specific activity in any built asset.

Comparatively, this is the second-most developed activity system across all three cases. The analysis (Figure 3) shows that Companies A and B have the most accomplished BIMbased maintenance management practices. Although Company $\mathrm{C}$ is resonably proficient, it has the lowest overall maturity in maintenance management.

\subsection{WORK-ORDER MANAGEMENT}

Company A utilises a BIM-based CMMS system to monitor its work-orders. Through these systems, work-orders are raised, processed, and monitored, and the summaries reported to senior management for strategic decision making. Within any period of choice, Company A can track how many service requests have been initiated, how soon they have been completed, and how many are still open. Thus, value is derived as the systems make it easier to troubleshoot, monitor service requests, provide feedback, speed-up action, 
reduce equipment idleness and improve task performance. On the other hand, Company $B$ has derived value from BIM-based processes through improved efficiency, data accuracy and the reduced time of operations. Through a BIM-based CMMS portal, endusers can access the building model in a 3D view, highlight a faulty asset or equipment, and raise a work-order. Once the work-order is raised, the system automatically generates all the information and is managed virtually with reference to the 3D building information model. Also, Company B utilises historical records for these work-orders to report regulatory compliance. In contrast, the BIM systems in Company C contain geometric information, including a room database, which is extracted to the BIM-based CMMS whenever there is an active service request. These systems enable operational personnel to track task performance, change the task status, and review preventive maintenance actions and progress.

Comparatively, this activity system has the third-highest average across all three cases. The analysis (Figure 3 ) shows that overall, Company A has the most systematic approach towards work-order management. Companies B and C are rated second and third, respectively.

\subsection{VALUE REALISATION MANAGEMENT}

Company A practices one method of value realisation, namely the annual customer satisfaction poll, which usually receives approximately 8,000 replies each year. Using a 15 Likert measurement scale, the end-users are asked to give feedback on details about the building in which they mainly work. Every response below the scale of 3 is allocated a textbox for more information. The KPI results are used to calculate the end-user experience, which inform the calculation of the contractor's incentives. The KPIs utilised are the attainment of a safe, healthy and productive working environment as well as the evaluation of indoor air quality. In contrast, Company B is currently in the process of formalising the benefits derived from BIM by writing white papers and developing business cases that prove a Return on Investment (ROI). They highlighted the development of a proof of concept where the use of BIM saved them an estimated $\$ 40,000$ and approximately 65 man-hours in a single maintenance task. Company B have strongly emphasised the importance of establishing value realisation as a business process and the validation of BIM business value within the organisation. They understand that without this validation, it would be difficult to demonstrate to senior management that there is business value in BIM during asset operations, which may impede the BIM rollout across the portfolio. On the other hand, there is a lack of formal processes to measure or validate BIM business value in Company C. Instead, they view BIM as a strategic solution to their complex coordination, communication, and data management problems during the product development. Company $\mathrm{C}$ acknowledges the organisational weakness of measuring benefits and attributes this to the BIM implementation strategy in their organisation, which is bottom-up. 
Comparatively, this activity system has the lowest average across all three cases. The analysis (Figure 3 ) shows that overall, Company A has the most organised approach to value realisation management. Companies $\mathrm{B}$ and $\mathrm{C}$ are the second and third, respectively. In comparison to Company $\mathrm{B}$, Company $\mathrm{A}$ has a more mature people dimension. Also, from the analysed data, Company $\mathrm{C}$ has the lowest maturity because there are currently no established organisational procedures for value realisation management within the organisation.

\subsection{SUMMARY OF RESULTS}

From the cross-case analysis, the following findings are deduced:

- Overall, Company A is the most proficient and Company $\mathrm{C}$ is the least developed.

- The case studies focus more on the activity system of BIM strategy in implementing BIM during asset operations.

- Maintenance management is the second most focused area for BIM implementation in asset operations.

- Value realisation management is the least developed area in BIM implementation in asset operations.

- Contract management is the second least focused activity system for BIM implementation in asset operations.

- The process dimension is the most developed BIM governance dimension in asset operation across all three cases.

- The people dimension is the least developed BIM governance dimension in asset operation across all three cases.

- There is no evidence that the asset owners' business sector influences the organisational value realisation approaches across all three cases

Furthermore, the BAMM tool (Munir et al., 2019) consists of five sequential tiers of maturity that demonstrate the development of an organisation in relation to its potential to realise BIM business value. They are: Tier 1: Ad-hoc (19-35); Tier 2: Defined (36-53); Tier 3: Managed (54-71); Tier 4: Integrated (72-89); and Tier 5: Optimised (90). The aggregate score from the cross-case assessment sheet (Figure 2) qualifies the level maturity of each case study. As such, all three cases have been appraised based on the cross-case assessment sheet (Figure 2) and are presented in the maturity model (Figure 6): 


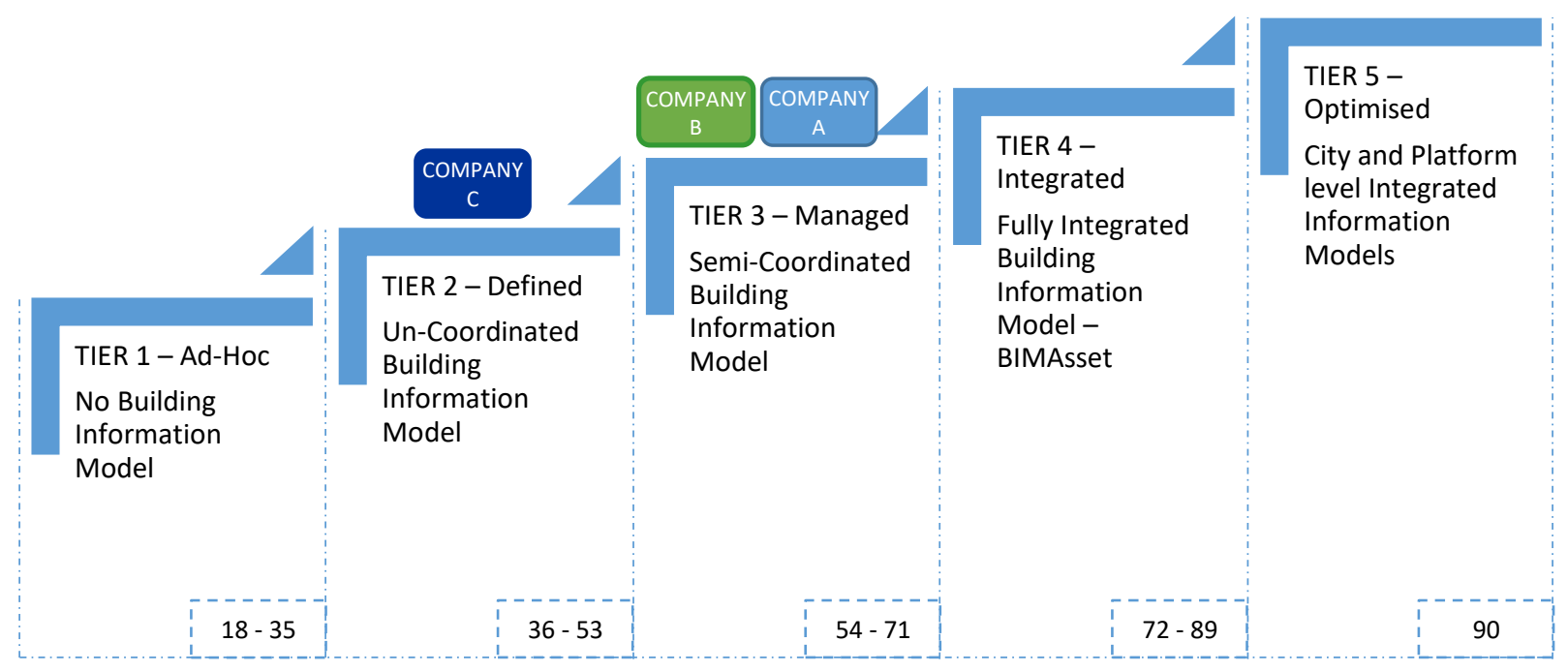

Figure 6: Maturity matrix for cross-case analysis adapted from Munir et al. (2019)

\subsection{DISCUSSION}

This study has revealed that the capability of asset owners to derive BIM business value in AM has implications for implementation and maturity. In the multi-case research, it was observed that the maturity of the activity systems impact on the ability of an asset owner to realise BIM business value. The results show that the proactive management of the six activity systems could help to develop organisational BIM maturity in order to achieve BIM business value. Furthermore, the research identified that asset owners across three sectors (government, health and education) place more emphasis on the activity system of the development of organisational BIM strategy. The findings have shown that asset owners are committing considerable resources to the development of robust BIM strategies that will enable BIM utilisation during asset operations. The development of a comprehensive BIM strategy is particularly important for asset owners to be able to understand the implications of BIM on organisational processes in relation to the lifecycle of the built asset. The planning and development of organisational measures on how BIM can support the delivery and management of built asset data will also guide the effective implementation of the other five activity systems (contract, lifecycle, maintenance, work-order and value realisation management). It is worth noting that all activity systems would require significant or similar attention for the asset owner to be able to realise sustainable BIM business value in AM. In addition, the study noted that the activity system with the least emphasis across all cases is value realisation management. This lack of development may be due to the inadequate level of understanding of the techniques and approaches for realising BIM business value by asset owners. All the three cases acknowledged the increasing organisational awareness concerning the need to qualify BIM business value, and the impetus to develop metrics to appraise the economic effects of BIM implementation in AM. Also, the respondents highlight the upsurge in management requests to justify BIM-based initiatives. The business process of measuring BIM business value in AM is complex, and for progress to 
be made in this subject area, a fundamental change is needed in the way asset owners manage BIM implementation and develop organisational BIM maturity. Similarly, this view is shared by a number of researchers (Mihindu and Arayici, 2008; Rowlinson et al., 2009; Watson, 2010; Arayici et al., 2011; Eadie et al., 2014).

On the other hand, the most developed BIM governance dimension is process, whereas people is the least developed. The results have demonstrated that asset owners are putting a lot of emphasis on developing process-based techniques for BIM implementation in AM. However, asset owners must give similar consideration to other BIM governance dimensions to sustainably improve the organisational potential of realising BIM business value. In addition, a significant contribution of this study is the identification of the following key activities that drive BIM business value in AM: BIM strategy, contract management, lifecycle management, maintenance management, workorder management and value realisation management. Also, the study answered the research questions by identifying the critical AM business processes that drive BIM business value in $\mathrm{AM}$ and how they relate to business process maturity.

\subsection{CONCLUSIONS}

The study aimed to identify the critical AM tasks that drive BIM business value for an asset owner. As such, this study identified six critical AM activity systems that drive business value, which cover a broad aspect of AM business processes during asset operations. The ability to realise business value from BIM-based processes depend upon the determination of the asset owner to continuously develop and improve all aspects of the activity systems from the organisational BIM dimensions of people, process and technology.

The findings in this study lead to five main conclusions. First, the study identified BIM strategy, contract management, lifecycle management, maintenance management, workorder management and value realisation management as critical activities that drive BIM business value for the asset owner in AM. Second, the asset owner could derive business value if the six activity systems are effectively executed and continuously improved to an advanced stage of maturity. Third, the most developed activity system is the BIM strategy, and the least is value realisation management across all cases. Fourth, the most proficient BIM governance dimension is Process, and the least is People across the three cases. Lastly, the study does not find any evidence that the asset owners' business sector influences the realisation of organisational value approaches across all cases. 


\section{REFERENCES}

Arayici, Y., Coates, P., Koskela, L., Kagioglou, M., Usher, C. and O'Reilly, K. (2011) 'BIM adoption and implementation for architectural practices', Structural Survey, vol. 29 , no. 1, pp. 7-25.

Bakis, N., Kagioglou, M. and Aouad, G. (2006) 'Evaluating the business benefits of information systems', In Proceeding of 3rd International SCRI Symposium, Salford Centre for Research and Innovation, University of Salford, Salford, UK.

Becerik-Gerber, B., Jazizadeh, F., Li, N. and Calis, G. (2012) 'Application areas and data requirements for BIM enabled facilities management', Journal of construction engineering and management, vol. 138, no. 3, pp. 431-442.

Bosch, A., Volker, L. and Koutamanis, A. (2015) 'BIM in the operations stage: bottlenecks and implications for owners', Built Environment Project and Asset Management, vol. 5 , no. 3 , pp. 331-343.

Boyatzis, R.E. (1998) Transforming qualitative information: thematic analysis and code development, $1^{\text {st }}$ edition, Thousand Oaks: Sage Publications, Inc.

Brous, P., Herder, P. and Janssen, M. (2015) 'Towards modelling data infrastructures in the asset management domain', Procedia Computer Science, vol. 61, no. 1, pp. 274-280.

Codinhoto, R. and Kiviniemi, A. (2014) 'BIM for FM: a case support for business life cycle', IFIP International Conference on Product Lifecycle Management. Advances in Information and Communication Technology. July 2014, Yokohama, 63-74.

Cruzes, D.S., Dybå, T., Runeson, P. and Höst, M. (2015) 'Case studies synthesis: a thematic, cross-case, and narrative synthesis worked example', Empirical Software Engineering, vol. 20, pp. 1634-1665.

Dakhil, A., Underwood, J. and Shawi, M. (2016) 'BIM benefits-maturity relationship awareness among UK construction clients', Proceedings of the First International Conference of the BIM Academic Forum, Held at Glasgow Caledonian University, Glasgow, September 13-15, 2016, Glasgow, UK.

Denscombe, M. (2010) The good research guide: for small-scale social research projects, $4^{\text {th }}$ edition, Maidenhead: McGraw-Hill International - Open University Press.

Eadie, R., Odeyinka, H., Browne, M., McKeown, C. and Yohanis, M. (2014) 'Building Information Modelling Adoption: An Analysis of the Barriers to implementation', Journal of Engineering and Architecture, vol. 2, no. 1, pp. 77-101.

Eisenhardt, K.M. (1989) 'Building theories from case study research', Academy of Management Review, vol. 14, no. 4, October, pp. 532-550, Available: https://www.uio.no/studier/emner/matnat/ifi/INF5571/v15/timeplan/ardocs/eisenhardt-1989.pdf [20 Jan 2019]. 
Guillen, A.J., Crespo, A., Gómez, J., González-Prida, V., Kobbacy, K. and S., S. (2016) 'Building information modeling as an assest management tool', IFAC-PapersOnLine, vol. 49, no. 28, pp. 191-196, Available: http://dx.doi.org/10.1016/j.ifacol.2016.11.033.

Henderson, K., Pahlenkemper, G. and Kraska, O. (2014) 'Integrated asset management: an investment in sustainability', Procedia Engineering, vol. 83, pp. 448-454.

Kiviniemi, A. and Codinhoto, R. (2014) 'Challenges in the implementation of BIM for FMcase Manchester town hall complex', Orlando, Florida, United States of America.

Love, P.E.D., Matthews, J., Simpson, I., Hill, A. and Olatunji, O.A. (2014) 'A benefits realization management building information modeling framework for asset owners', Automation in Construction, vol. 37, no. 1, pp. 1-10.

Love, P.E.D., Simpson, I., Hill, A. and Standing, C. (2013) 'From justification to evaluation: building information modeling for asset owners', Automation in Construction Volume, vol. 35, no. 1, pp. 208-216.

McArthur, J.J. (2015) 'A building information management (BIM) framework and supporting case study for existing building operations, maintenance and sustainability', 1104-1111.

Mihindu, S. and Arayici, Y. (2008) 'Digital construction through BIM systems will drive the re-engineering of construction business practices', Proceedings of the International Conference Visualisation, IEEE Computer Society, 9-11 July 2008, London, UK, 29-34.

Miles, M.B. and Huberman, M.A. (1994) Qualitative data analysis: an expanded sourcebook, $2^{\text {nd }}$ edition, Sage Publications, Inc.

Mobley, K.R. (2004) Maintenance fundamentals, $2^{\text {nd }}$ edition, Oxford: ButterworthHeinemann.

Munir, M., Kiviniemi, A. and Jones, S.W. (2018) 'Building Information Modelling (BIM) value realisation framework for asset owners', Proceedings of the 11th European Conference on Product and Process Modelling (ECPPM 2018), September 12-14, 2018, Copenhagen, Denmark, 313-320.

Munir, M., Kiviniemi, A., Jones, S.W., Finnegan, S. and Mêda, P. (2019) 'Development of a BIMAsset Maturity Model', Proceedings of the CIB W78 Conference, September 17-20, 2019, Northumbria, Newcastle, UK, 121-129.

Pärn, E.A., Edwards, D.J. and Sing, M.C.P. (2017) 'The building information modelling trajectory in facilities management: a review', Automation in Construction, vol. 75, pp. 45-55, Available: ISSN 0926-5805.

Parsanezhad, P. and Dimyadi, J. (2014) 'Effective facility management and operations via a BIM-based integrated information system', CIB Facilities Management (CFM) 2014 Conference, 21-23 May, 2014, Copenhagen, Denmark. 
Patton, M.Q. (2002) Qualitative evaluation and research methods, 3 $3^{\text {rd }}$ edition, Thousand Oaks: Sage Publications.

Rowlinson, S., Collins, R., Tuuli, M. and Jia, Y. (2009) 'Implementation of Building Information Modeling (BIM) in construction: A comparative case study', Proceedings of the 2nd International Symposium on Computational Mechanics and the 12th International Conference on the Enhancement and Promotion of Computational Methods in Engineering and Science, November 30 - December 2, 2009, Hong Kong and Macao, 572-577.

Sanchez, X.A., Mohamed, S. and Hampson, D.K. (2016) 'BIM benefits realisation management', in Sanchez, X.A., Hampson, D.K. and Vaux, S. (ed.) Delivering value with BIM: a whole-of-life approach, $1^{\text {st }}$ edition, London: Routledge.

Saunders, M., Lewis, P. and Thornhill, A. (2012) Research methods for business students, $6^{\text {th }}$ edition, Harlow: Pearsons.

Succar, B., Sher, W. and Aranda-Mena, G. (2007) 'A proposed framework to investigate Building Information Modelling through knowledge elicitation and visual models', Melbourne, Australia.

Vass, S. and Karrbom Gustavsson, T. (2014) 'The perceived business value of BIM', Proceedings at the 10th European Conference on Product and Process Modelling, ECPPM 2014, 17 September 2014 through 19 September 2014, Vienna, 21-25.

Watson, A. (2010) 'BIM - a driver for change. In Computing in Civil and Building Engineering', Proceedings of the International Conference on Computing in Civil and Building Engineering, 30 June-2 July, Nottingham, United Kingdom.

Yin, R.K. (2003) Case study research: design and methods, $3^{\text {rd }}$ edition, Thousand Oaks: Sage Publications, Inc. 